\title{
RBEP
}

\section{A história da educação na Rbep (1999-2011)}

Bruno Bontempi Jr.

\section{Resumo}

Trata-se de exame dos artigos de história da educação publicados na Revista Brasileira de Estudos Pedagógicos entre os anos de 1999 e 2011. Tem como objetivos: inventariar os temas principais, os períodos históricos tratados, os modos e critérios de periodizar, o léxico conceitual e os referenciais de análise presentes; relacionar esses caracteres ao perfil do periódico e aos padrões atuais de escrita, publicação e circulação dos resultados da pesquisa acadêmica na pós-graduação brasileira; ponderar sua representatividade no quadro das tendências apontadas pela historiografia e nos balanços, bem como o modo pelo qual respondeu às mudanças quantitativas e qualitativas conhecidas, desde meados de 1980, na história da educação praticada no Brasil. Conclui-se que o conjunto expressa algumas das características da atual historiografia da educação brasileira, mas não a espelha integralmente, pela incidência da ação seletiva e interveniente do campo educacional e do próprio periódico, para os quais a história da educação é um dos modos de abordagem de temas definidos no espectro dos problemas da educação.

Palavras-chave: historiografia da educação; periódicos; pesquisa em pós-graduação. 


\section{Abstract \\ The history of education in Revista Brasileira de Estudos Pedagógicos (1999-2011)}

It refers to examining the articles on history of education, which were published in Revista Brasileira de Estudos Pedagógicos, between 1999 and 2011. Its goals are to provide an inventory of the main themes, the historical periods, the modes and standards of the division in periods, the conceptual lexicon and the current analyses frameworks; to relate those characters to the journal's profile and to the current patterns of writing, publishing and circulation of academic research results in brazilian post-graduation courses; to consider its representativeness in the scope of historiography and confront it to the trends already shown in studies, as well as to investigate the way they responded to the previously recognized quantitative and qualitative changes made in the history of education since the mid-1980's in Brazil. One can conclude that these articles express some of the features of the current historiography of brazilian education, although they do not reflect it in full due to the incidence of the selective and intervening action from the educational field and from the journal, for which the history of education is one of the many ways to approach the issues defined in the spectrum of the problems in education.

Keywords: historiography of education; journals; research in post-graduate studies.

Qualquer pesquisa que realizarmos, tentando entender como o campo de história da educação é produzido, estará obrigatoriamente voltada para duas preocupações: o conteúdo dessa história e a organização institucional que lhe dá suporte. Tais preocupações aparecem quase sempre associadas, já que o exame dos produtos não exclui a análise dos lugares e das práticas que os instituíram.

(Nunes; Carvalho, 2005, p. 20)

\section{Introdução}

Para quem pretende seguir o método expresso nessa epígrafe, o primeiro desafio a enfrentar vem a ser justamente definir os lugares e as práticas que permitiram o aparecimento do conjunto de artigos 
de história da educação publicados na Revista Brasileira de Estudos Pedagógicos (Rbep) entre os anos de 1999 e 2011. Tenho por hipótese que suas características guardam relação não só com a linha editorial do periódico que os seleciona e os remodela, mas com a posição relativa da Rbep nas configurações histórica e atual do campo, expressando com nuanças próprias, em lugar de refleti-las inteiramente, as "tendências" que se têm verificado no conjunto da produção historiográfica da educação brasileira nos últimos anos.

A fim de identificar as "tendências" da história da educação praticada no Brasil, produção já bastante volumosa, vali-me de balanços (Xavier, 2001; Catani; Faria Filho, 2005; Araújo, 2005; Sá; Siqueira, 2005) e da análise que fiz da sucessão de eixos temáticos em cada uma das edições do Congresso Brasileiro de História da Educação (CBHE) - 2000-2011, organizado pela Sociedade Brasileira de História da Educação (SBHE). ${ }^{1}$ Como a seleção de trabalhos para eventos são proverbialmente menos restritivas do que para periódicos, como são os próprios autores que escolhem os eixos em que inscrevem suas comunicações, ${ }^{2}$ e como esses eixos são aprovados em assembleias gerais depois de terem sido propostos por comissões organizadoras locais, ${ }^{3}$ considerei que o sucessivo oferecimento de eixos e os variáveis índices de adesão são um critério de apuração das preferências da área, menos arbitrário e potencialmente arrevesado do que uma reunião de trabalhos em categorias definidas a posteriori. ${ }^{4}$

\section{O escopo da Rbep e a história da educação}

Comparando-se o foco e escopo da Revista Brasileira de Estudos Pedagógicos com o das principais revistas especializadas em história e historiografia da educação atualmente em circulação, conclui-se que, enquanto elas publicam materiais "vinculados [a essa] temática" (Cadernos de História da Educação, 2012), "relacionados à história e historiografia da educação" (Revista Brasileira de História da Educação, 2012), "pertinentes ao campo historiográfico" (Revista de História da Educação, 2012), "que abordam a História da Educação" (HISTEDBR On-line, 2012), a Rbep seleciona e publica "artigos inéditos de natureza técnico-científica, resultantes de estudos e pesquisas que contribuam para o desenvolvimento do conhecimento educacional e que possam oferecer subsídios às decisões políticas na área" (Rbep, 2012, grifos meus). Isso indica que a Rbep acrescenta como requisito um elemento que não é necessário, do ponto de vista de um historiador de ofício, para a escolha de um tema ou abordagem para investigar e sobre os quais escrever. Assim, o critério de "oferecer subsídios para decisões políticas", que guarda nítida relação com o caráter oficial original da publicação, não só influi sobre a decisão da comissão editorial de aceitar um original, como também sobre a fatura final, no caso de serem recomendadas ao autor alterações para atender a essa prescrição. De outra parte, essa exigência pode ter agido como obstáculo à submissão de artigos pelos historiadores
${ }^{1}$ A Sociedade Brasileira de História da Educação, fundada em 1999, é a entidade que congrega os praticantes da história da educação no Brasil. Desde 2000, vem promovendo bienalmente os congressos brasileiros de história da educação; em 2001, passou a publicar o periódico quadrimestral Revista Brasileira de História da Educação. Os quadros com os números referentes às inscrições em eixos temáticos nos sucessivos congressos estão disponíveis na página eletrônica da entidade < http://www.rbhe.sbhe.org.br>. A fim de não poluir o texto com dados numéricos e tabelas, optei por trazer à análise apenas o que pude concluir de minhas operações com aqueles dados.

${ }^{2}$ Isto só não ocorreu no I Congresso, em que "a maioria dos pesquisadores não indicou explicitamente o eixo temático no qual pretendia incluir seus trabalhos, ficando esta tarefa de classificação a cargo da Comissão Organizadora" (Xavier, 2001, p. 219), que agrupou os trabalhos aceitos em oito "subtemas", salientando, porém, que "as fronteiras entre os vários temas são muito tênues" (Saviani, 2000, p. 1). Por ter sido feita pela comissão, a partição em subtemas gerou um equilíbrio numérico que distingue a primeira edição do evento das demais, em que a escolha do eixo temático coube aos inscritos.

${ }^{3}$ Há expectativa de que os eixos expressem as "linhas de interesse" da comunidade de praticantes, como indica este trecho da apresentação do VI CBHE: "Para além do tema central, os eixos temáticos, discutidos e aprovados pelos sócios em assembleia realizada em outubro de 2007, em Caxambu, por ocasião da $30^{\mathrm{a}}$ Reunião Anual da Associação Nacional de Pós-Graduação e Pesquisa em Educação (ANPEd), apontam as linhas de interesse que têm aglutinado os trabalhos de pesquisa em nível nacional. Eles nortearão a organização das sessões de comunicações e pôsteres, além das comunicações coordenadas e organizadas pelos grupos de pesquisa ou por pesquisadores atraídos por um tema de discussão." (Comissão Organizadora, 2012).

${ }^{4}$ Nisto parece concordar Saviani (2000, p.1), ao comentar a distribuição de trabalhos em "subtemas", no I Congresso: "[...] vários trabalhos poderiam ser situados em diferentes subtemas. Isso certamente permitiria aumentar o número de textos do subtema 'Imprensa Pedagógica', já que alguns trabalhos tratam, por exemplo, do pensamento 
educacional pela via do modo como as ideias foram veiculadas por jornais ou revistas, o que tornaria possível o seu enquadramento tanto no subtema 'Pensamento educacional' como em 'Fontes, categorias e métodos de pesquisa em história da educação' ou 'Imprensa pedagógica'. O mesmo raciocínio poderia se feito com os outros subtemas, cujos trabalhos poderiam, a partir de um critério diverso de ordenação, ser enquadrados em um subtema diferente daquele que lhe foi atribuído."

${ }^{5}$ Verifica-se, a propósito, que não foram publicados artigos de história da educação na Rbep nos anos de 2001, 2002, 2004 2006 e 2009. Em 2005 e 2011 , registra-se apenas um artigo da especialidade por ano. "desinteressados", de modo a se tornarem para eles mais atraentes os periódicos da especialidade, cuja multiplicação nos anos 2000 bem poderia explicar o reduzido número de artigos de história da educação que vêm sendo publicados nas revistas da área.

A obediência ao escopo da publicação instaura, portanto, um primeiro fator de diferenciação entre a natureza do que de ordinário se publica neste periódico e o que se pode publicar ou comunicar nos foros reservados aos praticantes da "pura" historiografia da educação. Desse modo, ainda que os que publicaram na Rbep possam ser usualmente praticantes dessa forma "autônoma" de escrita histórica, a limitação imposta pelo escopo editorial deve ser minimamente ponderada, de modo a que o corpus em análise não seja imediatamente identificado com as tendências admitidas como dominantes nessa especialidade. Não obstante, o fato de a história da educação representar um segmento comumente reduzido no conjunto dos artigos publicados nas revistas especializadas em educação ${ }^{5}$ é indicativo de uma seletividade específica, que leva em conta a qualidade dos originais e sua pertinência ao campo educacional, além do caráter "aplicado" do conhecimento histórico. Os artigos em tela, por terem sido aceitos para publicação em uma revista que não é exclusivamente de história da educação, tendem a ser menos autônomos, ou seja, são orientados em menor grau por interesses e critérios intrínsecos à especialidade, para que possam obedecer aos da revista que os recebe, solicita modificações e os aceita mediante critérios e interesses da área, inscritos nos comitês de editoria e assessoria.

A pergunta que surge a respeito do conjunto de artigos desse corpus é a seguinte: Pode ser ele considerado como uma amostra representativa da produção recente nesta especialidade, ou trata-se de um conjunto peculiar, marcado em seus caracteres por fatores tais como o perfil do periódico e a ação seletiva da "área" sobre a "especialidade"? Está evidente nessa pergunta a concordância com Chartier (1990), de que as ideias expressas em um texto não podem ser adequadamente pesadas sem a consideração de seu suporte e das operações que permitiram sua produção e circulação. Ao questionar o quanto esse corpus se encontra vincado pelas interferências do periódico que o porta, de modo a não espelhar imediata e fielmente as tendências do campo dos historiadores, nego primeiramente a hipótese de que possa haver critérios puramente objetivos pelos quais um autor faça a escolha do veículo em que pretende fazer circular o seu texto, assim como para que os avaliadores o autorizem. Além disso, afirmo a existência dos campos da "educação" e da "história da educação" em que "área" e "especialidade" ou "subárea" não se afiguram apenas como relação epistemológica de contingência, mas como uma relação de poder a induzir ou determinar escolhas, processos e critérios de avaliação e classificação dos textos - portanto, a definir sua forma final e o "enquadramento" aos leitores. Desnecessário é dizer que a relação entre os campos não tem apenas um vetor, e que diferentes veículos, controlados por um campo ou por outro, igualmente operam "distorções" entre as proporções e tendências que se identificam em cartografias panorâmicas e não perspectivadas. 
Outro aspecto a considerar é que, por não terem sido solicitados por demanda específica, ou seja, por não ter havido chamada da coordenação editorial para artigos em história da educação (por exemplo, para dossiês ou seção reservada à especialidade), as colaborações foram classificadas ad hoc para a feitura deste número. Isso significa que, somados aos artigos em que, no corpo do texto, no resumo ou nas palavras-chave os autores afirmaram ser o trabalho de história da educação, foram-me enviados também os que não o fizeram, mas que tomaram um tópico educacional em suas ocorrências no passado ou que estabeleceram um modo diacrônico de organização do argumento explicativo, indícios geralmente usados para classificar as iniciativas - presentes em todos os campos - de conferir historicidade a si próprios e a seus objetos. A questão transcende, porém, os limites da epistemologia quando se admite que o caráter "desinteressado" da história da educação constitui uma das bases da configuração histórica desse campo no Brasil, uma vez que ela passa pela afirmação da autonomia relativa de seus praticantes com relação à Pedagogia e, como correlato, pela obtenção de legitimidade entre os praticantes da história, adotando suas práticas e habitus. Como aponta Cordeiro (2005, p. 3),

\begin{abstract}
A constituição de uma associação científica nacional [SBHE] e de um periódico especializado [RBHE] parece revelar a intenção de emancipar a área dos estudos históricos em educação dessa heteronomia do discurso pedagógico, expressando sua institucionalização mais efetiva no país. É como se os pesquisadores da área demarcassem um território específico, particular, recortado na intersecção entre campos ou subcampos distintos, e que passa a se definir com pretensão de autonomia intelectual, delineando-se, a partir daí, a possibilidade de determinar, entre os pares, objetos, fontes, problemas e questões, opções teóricas e metodológicas e formas de avaliação da qualidade das investigações e de publicação dos seus resultados.
\end{abstract}

Logo, como a conquista de autonomia e legitimidade pelo campo de história da educação brasileira teve como bandeiras a liberdade de escolha de temas e problemas, o direito de estabelecer as próprias finalidades e a emulação do ethos do historiador de ofício, pode-se cogitar, invertendo o vetor das lutas pela demarcação de lugares, que alguns dos artigos do conjunto em tela não teriam sido publicados em revistas da especialidade, seja por não se reportarem a autores e obras canônicos, seja por "desrespeitarem" procedimentos inerentes ao historiador, por exemplo, a "crítica das fontes". ${ }^{6}$

\section{Os artigos}

A começar, porém, por propriedades extrínsecas aos textos do conjunto, um aspecto a destacar é que apenas até 2003 há artigos de autoria exclusiva de não doutores, de modo que o doutoramento, dominantemente, mas não exclusivamente em Educação, passa a ser desde

\footnotetext{
${ }^{6}$ Inspirado no procedimento de "objetivar o sujeito objetivante" (Bourdieu, 1990), esclareço que tanto as marcas de minha formação quanto o meu pertencimento e exercício no campo da história da educação me impedem de "desincorporar" o ponto de vista inerente. Portanto, as análises que se seguem devem ser ponderadas pelo leitor como não mais do que uma refração desse prisma.
} 
${ }^{7}$ Apesar de constar sua condição de professor adjunto na Universidade Estadual do Rio Grande do Norte, foi como doutorando da Universidade de São Paulo que Gilson Pereira (1999) submeteu o seu original. A identificação e classificação de sua origem como sendo de São Paulo resulta coerente, aliás, com o objeto de sua pesquisa.

${ }^{8}$ Essa repetição de autores em curto período interfere, como será visto, no perfil da produção considerada.

${ }^{9}$ Entre 1990 e 2005, foram criados quase duas dezenas de Programas de Pós-Graduação em Educação fora do eixo Rio de Janeiro, São Paulo e Minas Gerais; sete deles na Região Sul, dez na Região Nordeste e dois na Região Norte. Nem todos, entretanto, têm linhas que contemplem a história da educação (Gondra, 2005). então a titulação da totalidade dos colaboradores, em sua maioria docentes credenciados em programas de pós-graduação em Educação. A alta titularidade dos autores marca a seletividade e de pronto as diferenças entre os suportes "periódico" e "anais", nos quais a produção da área e da especialidade é divulgada, sendo os eventos mais "permeáveis", por congregarem em maior grau os diferentes níveis de formação e experiência de seus pesquisadores.

A distribuição dos autores por instituições de ensino e pesquisa em unidades federativas, que não é passível de seleção, revela o predomínio do Rio de Janeiro, com autoria de $44 \%$ dos artigos, seguido de São Paulo, com 33\%. ${ }^{7}$ Se somado a eles a contribuição de uma autoria mineira, chega-se a 83\% de autorias fixadas na Região Sudeste. As Regiões Sul e Nordeste não estão representadas nesse corpus, e há dois artigos de autores de universidades do Centro-Oeste, mais um da Região Norte. Dentro da região majoritariamente representada nota-se o predomínio de São Paulo no início da série (de 1999 a 2005) e o amplo predomínio do Rio de Janeiro de 2006 a 2011, período em que o Estado paulista já não figura. Um cotejamento mais detalhado tende a favorecer ainda mais o Rio de Janeiro, ao se considerar como um desvio a presença de três artigos (16\%) assinados por uma mesma dupla de autores (Ferreira Jr.; Bittar, $1999,2000,2003)$ sediada em uma instituição paulista. ${ }^{8}$

Dessa configuração resulta que, no conjunto, apenas o estudo de Rizzini (2007), da UFRJ, apresenta enfoque regional fora da Região Sudeste; os trabalhos enviados por autoras sediadas em Mato Grosso (Ferreira, 2008), Mato Grosso do Sul (Valente, 2000) e no Ceará (Vieira, 2007) são de âmbito nacional, contrariando a expectativa de que manifestassem a predominância atual dos enfoques regionais nas Regiões Centro-Oeste (Sá; Siqueira, 2005), Norte e Nordeste (Araújo, 2005). Com efeito, tanto o movimento de expansão dos centros irradiadores de pesquisa em educação como o perfil da produção historiográfica têm apresentado tendência oposta, ou seja, de maior distribuição dos praticantes e de "regionalização" de temas e problemas. Há diversos fatores que vêm estimulando essa tendência, dos quais o movimento crítico e de superação da historiografia que se estabeleceu e cristalizou desde o século 19 (Bontempi Jr.; Hisldorf, 2011), que consiste, grosso modo, na tradição de ignorar, menosprezar ou subsumir as realidades regionais nas interpretações sobre a história da educação brasileira; o crescimento da pós-graduação no País, que agiu como fator de fixação e formação dos pesquisadores em suas regiões e culturas de origem, permitindo uma distribuição institucional mais descentralizada, ${ }^{9}$ e, na confluência desses fatores, a valorização do uso de fontes documentais ditas "primárias" para a feitura e validação de trabalhos acadêmicos em história da educação, o que conduziu a iniciativas de busca, organização e disponibilização dessa "matéria-prima" em âmbito local e regional.

Na própria história da formação do campo há recorrências que indicam esse movimento. Nas reuniões anuais do Grupo de Trabalho História da Educação na Associação Nacional de Pós-Graduação e Pesquisa 
em Educação (ANPEd), o valor do "regional" entra em pauta em fins da década de $1980 .{ }^{10}$ De acordo com Catani e Faria Filho (2005, p. 91), entre as preocupações centrais do GT em 1988 figuravam as "questões relativas à produção de uma historiografia da educação local, seus problemas e possibilidades" (grifo meu). Na reunião do ano seguinte, noticia-se o surgimento de "núcleos de história da educação criados em alguns estados" (2005, p. 92), exprimindo o início da descentralização de centros irradiadores da produção, a se intensificar nas décadas seguintes. Em 1991, já se anuncia o "regional" como "eixo teórico-metodológico na produção da pesquisa e no ensino de história da educação" (2005, p. 96). No final da década, por ser considerada uma das "questões mais candentes da educação brasileira sob os aspectos da história e da historiografia" e "um problema teórico-metodológico de grande importância" (Saviani, 2000, p. 1), a questão do "nacional e [do] regional na história da educação brasileira" aparece como tema de mesa-redonda da primeira edição do CBHE. Há mais: na esteira de valorização das "fontes primárias", a Sociedade Brasileira de História da Educação, tendo identificado "lacunas na disponibilização de fontes oficiais sobre as diferentes unidades federativas" (Saviani et al., 2011, p. 39), passa a publicar em parceria com o Instituto Nacional de Estudos e Pesquisas Educacionais Anísio Teixeira (Inep) a Coleção Documentos da Educação Brasileira, facilitando o acesso à documentação legislativa de vários Estados. ${ }^{11}$ Por fim, indício expressivo do crescimento do número de pesquisadores fora do eixo central, particularmente no Nordeste e Norte, é a explosão do volume de trabalhos aceitos no V Congresso, em Aracaju, em 2009: de uma média de 437,5, nas duas edições anteriores, para 783 (CBHE, VI, 2012), retornando ao padrão anterior no evento seguinte, realizado na Região Sudeste. Ainda que não apareça de modo explícito nos títulos de eixos temáticos nos eventos nacionais, a tendência à regionalização é bastante clara na especialidade história da educação; logo, no que tange a ela, esse conjunto de artigos, dominantemente escritos por pesquisadores sediados nos dois maiores centros da pós-graduação brasileira, não espelha a configuração atual do campo historiográfico.

Os artigos em análise poderiam ser agrupados de diversos modos segundo seus temas, pois não só sobre cada tema incidem tópicas complementares, tais como fontes ou categorias de análise que poderiam igualmente ser usadas para sua classificação. Procurando respeitar o máximo as escolhas dos autores, seus objetivos e enfoques, agrupei os artigos em temas, obtendo como resultado um leque bastante variado, pois ao todo sete temas não são repetidos no período, indicando a variedade que tem sido apresentada nos balanços da área com a qual esse corpus parece estar em coerência: profissão docente, gênero, teoria da história da educação, movimentos sociais e educação, escrita e ensino de história da educação, intelectuais da educação, estatística escolar, diversidade cultural, história do ensino de matemática. Com mais de uma ocorrência verificam-se dois estudos sobre ensino e escolas militares, quatro estudos sobre políticas públicas em educação e cinco estudos sobre educação católica. Quanto aos temas que se repetem, destaco um que é pouco frequentado no campo historiográfico, o ensino militar, expressão que não
10 A importância do Grupo de
Trabalho História da Educação
da ANPEd para o campo de
história da educação brasileira
é reiteradamente apresentada
em seus balanços e memórias.
De acordo com Saviani et al.
(2011, p. 17), o GT "expandiu
o movimento de revisão crítica
dos padrões historiográficos
dominantes, funcionando como
espécie de caixa de ressonância
desse movimento e ampliando
a interlocução entre os pes-
quisadores da área. Ao mesmo
tempo, o GT funcionou como
núcleo difusor da nova produção
historiográfica que vinha sendo
gestada nos centros universi-
tários de pós-graduação mais
dinâmicos do País, irradiando-a
para outros centros de ensino e
pesquisa".
11 Os volumes trazem a docu-
mentação oficial (Leis e Regula-
mentos da Instrução Pública) das
províncias de Mato Grosso, do
Paraná, do Rio Grande do Sul, do
Rio Grande do Norte e da Paraíba. 
aparece nos títulos de eixos temáticos dos congressos, tanto é que uma versão reduzida de "Doutores ou soldados? O debate sobre o ensino militar no Império" (Cunha, 2008) foi inscrita no IV CBHE (SBHE, IV, 2006, p. 58) sob o eixo temático "Culturas e práticas escolares". A repetição do tema educação católica também chama a atenção, mas sua recorrência deve ser ponderada pelo fato de ser ela o tema dos mencionados três artigos da mesma dupla que procedem à crítica das práticas e dos discursos dos jesuítas no Brasil colonial. O aspecto que mais aproxima o perfil temático do conjunto de artigos de história da educação publicados na Rbep às tendências da especialidade vem a ser a recorrência do tema relativo a "políticas educacionais", que aqui aparece em estudos de reformas, das constituições e dos centros de pesquisa oficiais.

Como observei em outra oportunidade (Bontempi Jr., 1995), trata-se de um tema, tão antigo quão frequente entre os historiadores da educação brasileira, que atravessou mudanças paradigmáticas e, mesmo em tempos de hegemonia da história cultural, segue atraindo boa parte de seus praticantes, até porque a nova história política está imbuída dos alicerces da própria história cultural ou da história social. Acompanhando a evolução do tema como eixo de congressos, verifica-se que na primeira edição do CBHE (2000), em que os participantes não escolheram os "subtemas" em que foram agrupados, "Estado e políticas educacionais" teve o mesmo número de ocorrências, ao lado de "fontes, categorias e métodos". Trata-se, aparentemente, da coexistência de modos e preferências respectivamente antigos e novos. Porém, pelo exame da trajetória das palavras que compõem o "subtema", observa-se a manutenção do interesse pelo Estado e suas políticas, apesar dos variados arranjos feitos pelas comissões organizadoras: em 2002, a palavra "Estado" aparece associada a "etnias" e "nação", mas essa composição tem procura bastante reduzida. Já "políticas educacionais" mantém-se bastante estável: tem o segundo lugar das preferências em 2004, quando associadas a "modelos pedagógicos", e em 2008, quando associadas a "intelectuais da educação e pensamento pedagógico". Em 2006, aparecem em terceiro lugar, quando se associam a "movimentos sociais" e alavancam a procura por essa categoria. Em 2011, a vinculação explícita entre Estado e políticas educacionais retorna como eixo, o que lhe permite mostrar todo seu vigor, sendo então o terceiro eixo mais procurado. Pode-se dizer, portanto, que a antiga tendência de interlocução com o Estado, com a correlata preferência por suas ações e fontes por ele emanadas (Warde, 1984), certamente não se encontra em declínio.

Sem embargo da semelhança sugerida pela preferência pelas políticas educacionais, tenho por hipótese que sobre o corpus aqui analisado tenha pesado um fator intrínseco ao próprio periódico e que se manifesta na presença de dois estudos, em menos de dez anos, sobre os Centros de Pesquisa do Inep, instituição governamental que abriga a Rbep: trata-se dos artigos de Libânia Xavier (1999) e Márcia Ferreira (2008) em torno da idealização, organização e produção do Centro Brasileiro de Pesquisas Educacionais (CBPE) e dos Centros Regionais de Pesquisas Educacionais 
(CRPEs). Essa concentração indica que as autoras podem ter escolhido o veículo a submeter seus originais pelo fato de as histórias que se dedicam serem de especial interesse para a publicação ou estarem de acordo com o foco e escopo da revista. No caso de Xavier (1999, p. 83), o indicia o seu "caráter informativo": "ao descrever para o leitor os dados sistematizados na pesquisa, espera-se estar contribuindo para ampliar o conhecimento sobre essa experiência institucional, fornecendo informações que podem contribuir para o desenvolvimento de futuros estudos sobre os temas presentes no recorte efetuado". No caso de Ferreira (2008, p. 73), o objetivo do artigo de interpretar o uso e as funções das pesquisas educacionais promovidas pelos Centros nas décadas de 1950 a 1970 é posto de modo explícito em sintonia com o foco e escopo da Revista e do Inep, "cujo propósito é gerar subsídios à tomada de decisões políticas acerca da educação". Nessa mesma chave poderia ser compreendido o artigo de Clarice Nunes (2000), biografia elogiosa do mais notório diretor da entidade, Anísio Teixeira, e apresentada como "versão condensada da conferência de abertura apresentada na 23 $3^{\text {a }}$ Reunião Anual da Associação Nacional de Pós-Graduação e Pesquisa em Educação (ANPEd) [...], em setembro de 2000 (p. 154)" - o que explica, em parte, o seu caráter "monumental".

Em balanço realizado na metade da década passada, Catani e Faria Filho (2005, p. 104) apontaram como "típicos dos anos de 1990" os temas "profissão docente", "fontes e metodologia", "estudos de gênero", "livros e práticas de leitura" e "saberes escolares". Estaria o corpus aqui analisado manifestando o temário daquele decênio? Não me parece. O primeiro tema listado aparece nesse corpus representado pelo artigo de Pereira (1999), enquanto o artigo de Almeida (2005) pode ser enquadrado como "estudo de gênero". De fato, "profissão docente" aparece como "carro-chefe" nos eixos temáticos de todas as edições de congresso, e sempre com grande número de trabalhos inscritos: em 2000, figura em segunda posição; em 2002, associado a "culturas escolares", atinge o primeiro. Em 2004, fica no quarto posto, mas, em 2006, adicionado a "instituições escolares", chega ao primeiro lugar. Em 2008, associada a "instituições escolares formadoras", cai para terceiro lugar, mas com a maior procura em números absolutos de toda a série. Em 2011, é o quarto eixo mais procurado mas já se sustenta sozinho; trata-se, de fato, de um tema típico dos anos 1990, mas que permanece em voga no século 21. Quanto a "relações de gênero" em educação, de fato assunto em evidência no campo nos anos 1990, apresenta claro declínio na procura de inscritos ao longo dos anos 2000, mesmo quando associado a "etnia" e a "movimentos sociais", vindo a desaparecer na edição de 2011.

Quanto a livros, há dois trabalhos que deles tratam nesse conjunto, mas não de modo que possamos considerar como tema principal: o de Gondra e Silva (2011) investiga livros para o ensino de história da educação já na perspectiva de "circulação de modelos", 12 e o de Carvalho et al. (2000), que pode ser também associado a saberes ou disciplinas escolares - caso da Matemática. Há diferenças porém que, para além das coincidências temáticas, denotam níveis diferentes de relação dos

\footnotetext{
${ }^{12} \mathrm{O}$ caso de ensino de História da Educação em sua trajetória como eixo em congressos denota um caso de indução pela entidade, declarado em artigo de 2001 (Saviani et al., 2011, p. 33). Em busca de adesão, o tema permanece de 2004 a 2011 , apesar de sua procura mitigada, de seis em 2004 a quatro em 2006, sendo a opção menos procurada em 2008. Em 2011, fica atrás até mesmo do "estreante" patrimônio.
} 
${ }^{13}$ A interlocução com a especialidade também não se verifica no artigo de Valente (2000), que trata de "diferenças" e "diversidade cultural", e que talvez pudesse ser inscrito em um congresso de história da educação sob a rubrica "etnias", expressão que aparece nas edições desse evento associada a "gênero" (de 2000 a 2008), "movimentos sociais" (2008 e 2011), "Estado" e "nação" (2002). O exame das referências bibliográficas do artigo e de sua abordagem macroeconômica, porém, denota significativo alheamento com relação ao campo na atualidade. autores com o campo de história da educação. Enquanto Gondra e Silva (2011) efetivamente dialogam com a produção da especialidade, o artigo sobre Euclides Roxo (Carvalho et al., 2000) não se refere a obras sobre currículo, livros didáticos ou história das disciplinas escolares que circulam no campo há duas décadas, assim como estão ausentes de sua bibliografia títulos publicados em torno do ensino secundário e do Colégio Pedro II após os anos de $1970 .{ }^{13}$

Quanto a "fontes e metodologia", esta não é discussão central dos artigos, exceto em "História da educação e estatística escolar: o processo de escolarização em Minas Gerais no século 19", de Faria Filho e Rezende (1999), e como um dos tópicos da discussão teórica de Araújo (2007). Acompanhando a trajetória desses termos na composição dos eixos temáticos das edições dos congressos brasileiros de história da educação, nota-se que "Fontes, categorias e métodos em história da educação" nasce como um dos "subtemas" mais promissores, criados para reunir os trabalhos submetidos à edição de 2000. Em 2002, porém, quando se inaugura a tradição de oferecer eixos temáticos para as inscrições, este enunciado não aparece. Em 2004, a palavra "fontes" torna a fazer parte de um eixo, associada a "arquivos" e "historiografia". Com a sucessão dos eventos, nota-se que, ao mesmo passo que cresce e se mantém estável o interesse pelas fontes e pela organização de instituições que as preservam e disponibilizam, a "historiografia", que se associava a termos como "categorias", "métodos" e "fontes", tem trajetória acidentada pelos eixos, com associações que variam de "história comparada" a arquivos, cultura material e patrimônio e instituições de custódia, o que denota a sua pulverização e enfraquecimento como prática. Trata-se, é claro, da predominância do interesse de preservar e manter mananciais que garantam a continuidade da multiplicação de trabalhos acadêmicos em história, os quais, de uns tempos para cá, se tornaram impensáveis sem o recurso a fontes documentais, de preferência, inéditas.

Por que os arquivos? Não só porque é com relação a eles que o problema das fontes é mais complexo, mas também porque contém informações inestimáveis (muitas vezes inéditas), necessárias ao cotejo e crítica de informações proeminentes de outras fontes e da própria historiografia educacional já produzida. Sem a perspectiva arquivística, essa historiografia, no limite, inexiste. (Nunes; Carvalho, 2005, p. 32)

Infelizmente, a recíproca não é verdadeira, pois se tem mostrado perfeitamente possível fazer história da educação sem praticar a historiografia, entendida na acepção crítica sugerida pelas autoras, a julgar por sua recente e sintomática subsunção a "fontes e métodos" e sua justaposição à "história comparada". Tudo leva a crer que a "historiografia" vem-se reduzindo às práticas de balanço da produção, que têm sua utilidade como recenseamentos, mas que não são capazes de apontar tendências, tampouco, de formular críticas. Nesse particular, por evidência da ausência, o perfil do corpus em exame e do campo apresentam coincidência. 
No que tange a outro aspecto reiterado nos balanços, da variedade de fontes primárias com que se está escrevendo uma nova história da educação brasileira, o conjunto de artigos em análise indica o uso de fontes emanadas pelo governo ou por entidades diretamente vinculadas ao Estado (leis e decretos, relatórios e boletins, artigos de revistas, conferências, atas e pareceres), em quatro artigos; dois dos artigos têm como fonte principal a imprensa pedagógica (revistas de escolas e entidades); três deles, de mesma autoria, utilizam-se de compilações de cartas e sermões; dois trabalham com livros e artigos, e dois, com livros didáticos. Há ainda o uso da imprensa local (jornais de notícia), de páginas eletrônicas de instituições, de memórias e depoimentos publicados. A chamada pluralidade de fontes se manifesta nesse corpus, assim como a preferência pelas fontes emanadas do Estado, que segue bastante prestigiada na especialidade.

Um tema que está fora do foco dos artigos em análise, mas que tem presença marcante na história da educação brasileira atualmente praticada, é o das instituições escolares. É evidente que as escolas se encontram presentes com destaque variado em diversos deles (por exemplo, Paulilo, 2003; Almeida, 2005; Rizzini, 2007; Santos, 2007), mas, recorrendo aqui ao parâmetro usado neste artigo para comparar os conjuntos, é provável que, por falta de outras opções, apenas os referentes ao ensino militar tivessem sido inscritos na rubrica "instituições educacionais e científicas" na distribuição feita pela comissão de 2000. A trajetória das instituições escolares pelos congressos, a propósito, é curiosa, pois, não obstante o vigor mostrado no primeiro, elas são sucessivamente diluídas em eixos associados a "profissão docente", "currículos" e "disciplinas escolares". Ao reaparecerem, em 2011, como primeiro nome de um eixo, recebem o maior número de trabalhos de todo o certame. Trata-se, portanto, de um tema muito frequentado pelos historiadores da educação brasileira em seus congressos, bastante relacionado à chamada "caixa preta escolar", mas que pouco aparece no conjunto analisado.

Vale discutir, ainda, o contraste entre a predominância nos congressos da especialidade do estudo histórico das "práticas escolares e processos educativos" e sua escassez no corpus aqui analisado. Tendo surgido como "subtema" em 2000, é incorporado a "culturas escolares e profissão docente" (2002), "cultura escolar e práticas educacionais" (2004), "cultura e práticas escolares" (2006), "culturas escolares e práticas educativas" e "currículo, disciplinas e instituições escolares" (2008), e "história das culturas e disciplinas escolares". É evidente na composição dos eixos a manifestação do que afirmam os balanços da especialidade (Saviani et al., 2011, p. 31), que destacam a crescente tendência de "investigar a escola pela sua interioridade", que denota a atenção para a cultura e as práticas escolares e a correlata hegemonia da "nova história cultural". É indício dessa hegemonia a própria composição dos nomes dos eixos, quando são definidos por um conceito (cultura escolar), e não por um assunto. $\mathrm{O}$ potencial de indução dessa estratégia pode ser imaginado no exercício de supor que, sob hegemonia de uma outra forte tendência em ação no campo da história da educação brasileira, houvesse um eixo nomeado "modo de 
${ }^{14}$ No conjunto analisado, os seguintes artigos desenvolvem destacadamente a interlocução crítica com a produção pregressa ou contemporânea na especialidade: Faria Filho e Rezende (1999), André Paulilo (2003), Alberto Araújo (2007) e Irma Rizzini (2007), Márcia Ferreira (2008) e Miriam Chaves (2010). produção capitalista e organização escolar", no qual poderiam ter sido inscritos ao menos quatro dos artigos do conjunto examinado (Ferreira Jr.; Bittar, 1999, 2000, 2003; Valente, 2000). Não obstante, a história cultural se faz presente nesse conjunto, notadamente nos artigos de Faria Filho e Rezende (1999), Paulilo (2003) e Rizzini (2007), muito embora seja notável a preferência dos autores desse corpus pela sociologia de Bourdieu, cujas obras foram citadas em um terço dos artigos.

O autor português Alberto Filipe Araújo (2007), em "História cultural e história das ideias educativas: reflexões e desafios", destaca-se entre os demais por realizar uma modalidade de estudo bastante rara em nossa recente tradição historiográfica: a discussão teórica de categorias e modelos de análise. No Brasil, entretanto, a discussão sobre matrizes interpretativas e referenciais de análise, bem como a prática historiográfica, entendida como revisão crítica do conhecimento acumulado na especialidade e na área, vem-se mostrando frágil, et pour cause, a adoção de conceitos e pontos de vista nomeados não tem servido para que os autores infirmem ou desafiem uns aos outros a respeito das descobertas que fazem mediante o uso dessas ferramentas mentais. ${ }^{14}$ Pode-se tomar como exemplo de como poderia ser frutífera a destinação de algum tempo de nossas vidas para a discussão teórica e metodológica com os pares acadêmicos o caso de dois artigos desse conjunto: "Interesse e desinteresse no magistério oficial paulista (1902-1910)", de Gilson R. de M. Pereira, e "Regionalização da pesquisa e inovação pedagógica: os centros de pesquisas educacionais do Inep (1950-1960)", de Libânia Nacif Xavier, publicados em 1999. Em seu artigo, Pereira (1999, p. 29) pretende demonstrar que o proclamado desinteresse dos professores públicos do Estado de São Paulo nos anos 1900 "foi uma forma de estratégia adequada aos jogos propriamente simbólicos praticados no Estado de São Paulo durante o processo de constituição e autonomização do campo educacional". Escorado em Bourdieu, o autor reconhece, portanto, a existência de um "campo educacional" naquele momento e âmbito geográfico. O artigo de Xavier (1999), que se dedica à descrição da estrutura e do funcionamento do Centro Brasileiro e dos Centros Regionais de Pesquisas Educacionais nas décadas de 1950 a 1970, defende por sua vez que sua criação responde às estratégias dos "renovadores" a fim de "promover a especialização e a autonomização do campo Educacional" (p. 82). Ainda que Xavier compartilhe com Pereira o referencial de análise, os autores não se põem em diálogo (neste caso, efetivamente não o poderiam, pois seus trabalhos saíram publicados na mesmo edição), o que lhes permite identificar a existência de um campo educacional em diferentes tempos e lugares. Ora, ou bem os autores entram em contradição quanto à temporalidade e ao alcance do processo, que para Pereira estava em curso em São Paulo dos anos 1900, mas que para Xavier ocorre no Brasil dos anos 1950 e 1960, ou então tratam de um longo processo de cerca de meio século sem solução de continuidade. Se adicionássemos, porém, a afirmação de Ferreira (2008, p. 86) de que a extinção dos Centros nos anos 1970 denota a "pequena autonomia deste campo [educacional] em relação ao mundo da política", haveria de surgir 
uma ótima questão para pautar um debate historiográfico: Se houve, quando e em quais condições se deu a "autonomização do campo educacional" no Brasil? E haveria ainda muitas outras, se deixássemos para trás a era dos balanços e mergulhássemos na leitura intensiva das peças que compõem os grandes e festejados edifícios de nossa produção acadêmica.

\section{Considerações finais}

Neste ensaio procurei analisar os artigos de história da educação publicados na Revista Brasileira de Estudos Pedagógicos entre os anos de 1999 e 2011, cotejando algumas de suas características com as tendências que vêm sendo identificadas como dominantes na historiografia da educação brasileira em balanços produzidos nos últimos anos. Pude constatar a existência de similaridades e convergências entre essa produção e aquelas tendências, mas também a manifestação nesse corpus de peculiaridades que procurei relacionar à natureza do periódico e ao modo como área e especialidade estão implicadas na produção e distribuição de sua produção nos foros acadêmicos. Do ponto de vista metodológico, os resultados dessa experiência de trabalho e reflexão revelam a necessidade e a utilidade de retomarmos práticas historiográficas que verticalizem as análises, para que se chegue a profundidades ainda intocadas por balanços e panoramas.

\section{Referências bibiográficas}

ARAÚJO, Marta M. A produção em história da educação das Regiões Nordeste e Norte. O estado do conhecimento (1982-2003). In: GONDRA, J. G. (Org.). Pesquisa em história da educação no Brasil. Rio de Janeiro: DP \& A, 2005. p. 289-312.

BONTEMPI JR., Bruno. História da educação brasileira: o terreno do consenso. 1995. 117 f. Dissertação (Mestrado em Educação) - Pontifícia Universidade Católica de São Paulo (PUC-SP), 1995.

; HISLDORF, Maria Lucia S. Educação e instrução na província de São Paulo: no contraponto das vozes, três tendências e um desvão. In: GONDRA, José; SILVA, José Cláudio S. (Org.). História da Educação na América Latina: ensinar \& escrever. Rio de Janeiro: Eduerj, 2011. p. 55-82.

BOURDIEU, Pierre. Objetivar o sujeito objetivante. In: . Coisas ditas. São Paulo: Brasiliense, 1990. p. 114-118.

. A economia das trocas simbólicas. 3. ed. Tradução de Sérgio

Miceli et al. São Paulo: Perspectiva, 1992. 371 p. 
CADERNOS DE HISTÓRIA DA EDUCAÇÃO. Foco e escopo. Disponível em: <http://www.seer.ufu.br/index.php/che/about/editorialPolicies\# focusAndScope2012>. Acesso em: 26 mar. 2012.

CATANI, Denice B.; FARIA FILHO, L. M. Um lugar de produção e a produção de um lugar: história e historiografia da educação brasileira nos anos de 1980 e de 1990. In: GONDRA, J. G. (Org.). Pesquisa em história da educação no Brasil. Rio de Janeiro: DP \& A, 2005. p. 85-110.

CHARTIER, R. A história cultural entre práticas e representações. Tradução de Maria Manuela Galhardo. Lisboa: Difel; Rio de Janeiro: Bertrand Brasil, 1990.

CONGRESSO BRASILEIRO DE HISTÓRIA DA EDUCAÇÃO (CBHE), III., 2004, Curitiba. Apresentação. Livro de resumos. Curitiba: Pontifícia Universidade Católica do Paraná/Sociedade Brasileira de História da Educação, 2004. Disponível em: < http://sbhe.org.br/novo/congressos/ cbhe3/paginas/cbhe.htm>. Acesso em: 2 mar. 2012.

IV., 2006, Goiânia. A educação e seus sujeitos na história. Cadernos de resumos. Goiânia: Vieira; Editora da UCG, 2006.

CORDEIRO, Jaime F. P. A produção em história da educação no Brasil em três periódicos: perspectivas comparadas. In: Anais do V Congresso Brasileiro de História da Educação. Aracaju-SE: SBHE, 2005. p. 1-19.

GONDRA, J. G. (Org.). Pesquisa em História da Educação no Brasil. Rio de Janeiro: DP \& A, 2005.

NUNES, Clarice; CARVALHO, Marta M. C. Historiografia da educação e fontes. In: GONDRA, J. G. (Org.). Pesquisa em história da educação no Brasil. Rio de Janeiro: DP \& A, 2005.

REVISTA BRASILEIRA DE ESTUDOS PEDAGÓGICOS. Foco e escopo. Disponível em: < http://rbep.inep.gov.br/index.php/RBEP/about/editorial Policies\#focusAndScope>. Acesso em: 26 mar. 2012.

REVISTA BRASILEIRA DE HISTÓRIA DA EDUCAÇÃO. Foco e escopo. Disponível em: < http://www.rbhe.sbhe.org.br/index.php/rbhe/about/ editorialPolicies\#focusAndScope >. Acesso em: 4 abr. 2012.

REVISTA HISTÓRIA DA EDUCAÇÃO (HISTEDBR). Foco e escopo. Campinas-SP, n. 44, dez. 2011. Disponível em: <http://seer.ufrgs.br/ asphe/about/editorialPolicies\#focusAndScopeASPHE > . Acesso em: 26 mar. 2012. 
REVISTA HISTÓRIA DA EDUCAÇÃO (HISTEDBR). Normas editoriais. Campinas-SP, n. 44, dez. 2011. Disponível em: < http://www.histedbr.fae. unicamp.br/revista/edicoes/44/index.html>. Acesso em: 26 mar. 2012.

SÁ, Nicanor P.; SIQUEIRA, Elizabeth M. A produção em história da educação na Região Centro-Oeste: perspectivas (1992-2004).

In: GONDRA, J. G. (Org.) Pesquisa em história da educação no Brasil. Rio de Janeiro: DP \& A, 2005. p. 313-340.

SAVIANI, Dermeval et al. Sociedade Brasileira de História da Educação: constituição, organização e realizações. Revista Brasileira de História da Educação, Campinas-SP, v. 11, n. 3, p. 13-45, set./dez. 2011.

SAVIANI, Dermeval. Apresentação. In: CONGRESSO BRASILEIRO DE HISTÓRIA DA EDUCAÇÃO, I., 2000, Rio de Janeiro. [Resumos]. Rio de Janeiro: Sociedade Brasileira da História da Educação/Faperj/Prefeitura do Rio/CNPq/Fapesp. 1 CD-ROM. Disponível em «http://sbhe.org.br/ novo/congressos/cbhe1/apresentacao.htm». Acesso em: 13 abr. 2012.

WARDE, Miriam J. Anotações para uma historiografia da educação. Em Aberto, Brasília, n. 32, p. 1-6, out.1984.

XAVIER, Libânia. Particularidades de um campo disciplinar em consolidação: balanço do I Congresso Brasileiro de História da Educação (RJ/2000). In: SBHE (Org.). Educação no Brasil. Campinas-SP: SBHE; Autores Associados, 2001.

\section{Artigos da Rbep (1999-2011)}

ALMEIDA, Jane S. Coeducação ou classes mistas? Indícios para a historiografia escolar (São Paulo, 1870-1930). Revista Brasileira de Estudos Pedagógicos, Brasília, v. 86, n. 213/214, p. 64-78, maio/dez. 2005.

ARAÚJO, Alberto F. História cultural e história das ideias educativas: reflexões e desafios. Revista Brasileira de Estudos Pedagógicos, Brasília, v. 88, n. 220, p. 459-476, set./dez. 2007.

CARVALHO, João Bosco P. et al. Euclides Roxo e o movimento de reforma do ensino de Matemática na década de 30. Revista Brasileira de Estudos Pedagógicos, Brasília, v. 81, n. 199, p. 415-424, set./dez. 2000.

CHAVES, Miriam W. Revistas de escolas católicas do Rio de Janeiro nos anos 1920-1950: religião e educação. Revista Brasileira de Estudos Pedagógicos, Brasília, v. 91, n. 228, p. 424-444, maio/ago. 2010. 
CUNHA, Beatriz R. C. Doutores ou soldados? O debate sobre o ensino militar no Império. Revista Brasileira de Estudos Pedagógicos, Brasília, v. 89, n. 222, p. 352-364, maio/ago. 2008.

FARIA FILHO, Luciano M.; REZENDE, Fernanda M. História da educação e estatística escolar: o processo de escolarização em Minas Gerais no século 19. Revista Brasileira de Estudos Pedagógicos, Brasília, v. 80, n. 125, p. 197-211, maio/ago. 1999.

FERREIRA JÚNIOR, Amarilio; BITTAR, Marisa. Educação jesuítica e crianças negras no Brasil Colonial. Revista Brasileira de Estudos Pedagógicos, Brasília, v. 80, n. 196, p. 472-482, set./dez. 1999.

; _. Infância, catequese e aculturação no Brasil do século XVI. Revista Brasileira de Estudos Pedagógicos, Brasília, v. 81, n. 199, p. 452-463, set./dez. 2000.

; A pedagogia da escravidão nos Sermões do Padre Antonio Vieira. Revista Brasileira de Estudos Pedagógicos, Brasília, v. 84, n. 206/207/208, p. 43-53, jan./dez. 2003.

FERREIRA, Márcia S. Usos e funções dos estudos promovidos pelos Centros de Pesquisas do Inep entre as décadas de 1950 e 1970. Revista Brasileira de Estudos Pedagógicos, Brasília, v. 89, n. 221, p. 72-89, jan./abr. 2008.

GONDRA, José G.; SILVA, José Cláudio S. Textbooks in the History of Education: notas para pensar as narrativas de Paul Monroe, Stephen Duggan e Afranio Peixoto. Revista Brasileira de Estudos Pedagógicos, Brasília, v. 92, n. 232, p. 702-722, set./dez. 2011.

NUNES, Clarice. Trajetória intelectual e identidade do educador: Anísio Teixeira (1900-1971). Revista Brasileira de Estudos Pedagógicos, Brasília, v. 81, n. 197, p. 154-166, jan./abr. 2000.

PAULILO, André Luiz. Sobre as políticas públicas de educação na cidade do Rio de Janeiro entre 1922-1935. Revista Brasileira de Estudos Pedagógicos, Brasília, v. 84, n. 206/207/208, p. 54-66, jan./dez. 2003.

PEREIRA, Gilson R. M. Interesse e desinteresse no magistério oficial paulista (1902-1910). Revista Brasileira de Estudos Pedagógicos, Brasília, v. 80, n. 194, p. 28-41, jan./abr. 1999.

RIZZINI, Irma. Experiências escolares na Amazônia Imperial: queixas de pais e moradores na imprensa paraense (1876-1888). Revista Brasileira de Estudos Pedagógicos, Brasília, v. 88, n. 220, p. 496-515, set./dez. 2007. 
SANTOS, Miriam de O. Um olhar sobre as instituições escolares militares brasileiras do fim do século 19 ao início do século 20. Revista Brasileira de Estudos Pedagógicos, Brasília, v. 88, n. 219, p. 310-330, maio/ago. 2007.

VALENTE, Ana Lúcia E. F. Quando as diferenças são um "problema"? Revista Brasileira de Estudos Pedagógicos, Brasília, v. 81, n. 197, p. 64-75, jan./abr. 2000.

VIEIRA, Sofia L. A educação nas constituições brasileiras: texto e contexto. Revista Brasileira de Estudos Pedagógicos, Brasília, v. 88, n. 219, p. 291-309, maio/ago. 2007.

XAVIER, Libânia N. Regionalização da pesquisa e inovação pedagógica: os Centros de Pesquisas Educacionais do Inep (1950-1960). Revista Brasileira de Estudos Pedagógicos, Brasília, v. 80, n. 194, p. 81-92, jan./abr. 1999.

Bruno Bontempi Jr., doutor em Educação pela Pontifícia Universidade Católica de São Paulo (PUC-SP), com pós-doutorado no Programa de História da Universidade do Estado do Rio de Janeiro (UERJ), é professor do Departamento de Filosofia da Educação e Ciências da Educação e orientador do Programa de Pós-Graduação em Educação da Faculdade de Educação da Universidade de São Paulo (FEUSP).

bontempi@usp.br 